\title{
O PESSOAL É POLÍtico: A CRÍTICA FEMINISTA DE NANCY FRASER E CATHERINE MACKINNON A JÜRGEN HABERMAS
}

Camila Palhares Barbosa ${ }^{1}$

Tatiana Vargas Maia ${ }^{2}$

Resumo: O presente artigo tem como objetivo analisar as críticas feministas elaboradas por Nancy Fraser e Catherine MacKinnon à teoria política proposta por Jürgen Habermas. Adotando um recorte de gênero para analisar as propostas avançadas por Habermas, tanto Fraser como MacKinnon desenvolvem conclusões semelhantes: ainda que a articulação sócio-política de Habermas seja interessante - inclusive em sua tentativa de abarcar e contemplar demandas do movimento feminista - a teoria habermasiana é falha em admitir uma das principais reivindicações e ponto de crítica fundamental do feminismo contemporâneo à teoria política que não parte de um recorte de gênero, qual seja, o não questionamento da ideia de separação nítida entre as esferas públicas e privadas. Como propósito de explicitar a articulação dessas críticas, propomos uma análise dos principais aspectos do agir comunicativo proposto por Habermas a partir de premissas feministas, na tentativa de centralizar questões de gênero na teoria habermasiana. Para tanto, primeiramente apresentamos uma leitura das noções das esferas do agir comunicativo e da diferenciação entre público e privado em Habermas através da crítica elaborada por Nancy Fraser. Em um segundo momento, discutimos perspectivas de poder e de razão, demonstrando sua problematização a partir da visão feminista radical de Catherine MacKinnon.

Palavras-chave: Feminismo, Jürgen Habermas, Nancy Fraser, Catherine MacKinnon.

Resumen: Este artículo tiene como objetivo analizar las críticas feministas desarrolladas por Nancy Fraser y Catherine MacKinnon a la teoría política de Jürgen Habermas. La adopción de un enfoque de género para analizar las propuestas presentadas por Habermas, tanto Fraser como MacKinnon desarrollan conclusiones similares: aunque la articulación sociopolítica de Habermas es interesante - incluso en su intento de abarcar y contemplar las demandas del movimiento feminista - la teoría de Habermas falla de admitir una de las principales demandas y punto fundamental de la crítica del feminismo contemporáneo a la teoría política que ninguna parte de la perspectiva de género, que es, sin cuestionar la clara separación de la idea entre las esferas pública y privada. El propósito de explicar la relación de estas críticas, se propone un análisis de los principales aspectos de la acción comunicativa propuesto por Habermas a partir de supuestos feministas, en un intento de centralizar las cuestiones de género en la teoría de Habermas. Para ello, en primer lugar, se presenta una relectura de la noción de esferas de acción comunicativa y la diferenciación entre lo público y privado en Habermas través crítica elaborada por Nancy Fraser. En un segundo paso, hemos discutido las perspectivas de poder y de razón, demostrando su cuestionamiento desde la visión feminista radical de Catalina MacKinnon. Palabras-clave: Feminismo, Jürgen Habermas, Nancy Fraser, Catherine MacKinnon.

Abstract: This article aims to analyze feminist critiques developed by Nancy Fraser and Catherine MacKinnon to Jürgen Habermas' theory. Adopting a gender approach to analyze this author's theoretical framework, both Fraser and MacKinnon reach similar conclusions: although Habermas socio-political articulation is interesting - even in its attempt to embrace and contemplate demands of the feminist movement - Habermas's theory fails to admit one of the main demands and fundamental point of criticism of contemporary feminism to political theory that does not adopts a gender perspective, that is, not questioning the clear separation between the public and private spheres. With the purpose of explaining the relationship between these criticisms, we propose an analysis of the main aspects of communicative action proposed by Habermas from a feminist perspective, in an attempt to centralize gender issues in Habermas' theory. To do so, we first present a reading of the notion of spheres of communicative action and the differentiation between public and private in Habermas through Nancy Fraser's criticism. In a second moment, we discuss the notions of power and reason, as advanced by radical feminist vision of Catherine MacKinnon. Keywords: Feminism, Jürgen Habermas, Nancy Fraser, Catherine MacKinnon.

\section{INTRODUÇÃO}

Em "Feminists read Habermas", Johanna Meehan $(1995,1)$ sugere que a Teoria do Agir Comunicativo apresenta reflexões acerca da política, da moral e das normas sociais que são fundamentalmente centrais para perspectivas feministas, uma vez que o feminismo tem como objeto as relações políticas e sociais que

\footnotetext{
${ }^{1}$ Mestranda do Programa de Pós-Graduação em Filosofia da Pontifícia Universidade Católica do Rio Grande do Sul (PUCRS). E-mail: camilabarbosa.ri@gmail.com.

${ }^{2}$ Professora de Relações Internacionais do Centro Universitário La Salle (Unilasalle). Doutora em Ciência Política pela Southern Illinois University (SIU). E-mail: vargasmaia@gmail.com.
} 
reproduzem noções de gênero e que criam tanto a dominação masculina quanto a subordinação feminina. Justamente por lidar com questões tão pontuais e atuais para as teorias feministas, essa autora aponta a teoria de Habermas como sendo de "grande interesse para teorias feministas apesar de sua falha em teorizar especificamente o gênero" (MEEHAN 1995, 1)3. A ausência de uma análise mais cuidadosa referente às relações entre gêneros que perpassam todas as esferas de ação comunicativa na apresentação de Habermas gerou críticas recorrentes por parte de diversas autoras feministas ${ }^{4}$. Nancy Fraser, em seu artigo "What's Critical about Critical Theory", publicado em 1995, propõe uma análise da Teoria do Agir Comunicativo através de reinvindicações feministas, problematizando as premissas assumidas por Habermas, ainda que, de acordo com Fraser, este "não tenha dito virtualmente nada sobre gênero na "Teoria do Agir Comunicativo" (FRASER 1995, 32). Para Fraser, as noções de diferenciação entre esfera pública-privada e a diferença social constitutiva entre produção material e simbólica concernem fundamentalmente para uma análise feminista de âmbito político e social (FRASER 1995, 32), assim como, a teoria crítica no geral precisa analizar mais cuidadosamente os termos público e privado, na medida em que podem legitimar e valorizar determinados interesses e desautorizar outros (FRASER, 1990, 73).

Esse déficit de considerações sobre questões de gênero na teoria habermasiana, contudo, não pode ser visto como algo deslocado ou periférico da proposta de restruturação das esferas comunicativas. O feminismo, enquanto teoria política e social, parte da premissa que a categoria sociológica de gênero é fundamental para a compreensão de dinâmicas estabelecidas entre grupos e indivíduos. bell hooks define o feminismo como o movimento que busca acabar com "o sexismo, a exploração sexista, e a opressão" (HOOKS 2000, 1) ${ }^{5}$. Seguindo essa linha de raciocínio, o argumento de grande parte das teóricas feminista é que independentemente de quais sejam as premissas - ontológicos, epistemológicas, políticas - adotas pelo movimento e pela teoria feminista, as mulheres, em termos globais, compartilham um ponto em comum, qual seja, sua opressão nas diversas esferas de atuação baseadas em papéis de gênero. A subordinação de mulheres em estruturas sexistas, portanto, muda completamente premissas e pressuposições de liberdade enquanto agentes discursivos e atuante nestas esferas. Assim, MacKinnon (1991, 3) afirma que para entender as relações de poder entre os gêneros é preciso saber como a desigualdade entre os sexos está sendo vivida, pois o status social da mulher é formado através das relações de sexo estabelecidas pelos homens e, portanto, questões de gênero perpassam todos os níveis institucionais, tanto na esfera privada quanto no mundo da vida ("lifeworld").

Em "Entre facticidade e veracidade", Habermas aborda ligeiramente questões relacionadas a políticas feministas, apresentando uma dialética progressiva de direitos entre igualdade de fatos e igualdade de direitos. Nesta obra, Habermas retoma alguns princípios anteriormente apresentados na Teoria do Agir Comunicativo, como por exemplo, esferas de dinâmicas de poder e relações interiores e exteriores da autonomia individual ${ }^{6}$. Amy Allen $(2012,354)$ afirma que em "Entre facticidade e veracidade", Habermas oferece uma revisão da noção de poder inspirada em noções de Arendt, que diferencia poder administrativo de poder social. Os tópicos desta revisão, que ficam bem especificados no que tange as perspectivas feministas nesta obra, contudo, permanecem sendo os mesmos questionados por teóricas como Fraser (1995; 1990), MacKinnon (1987; 1991).

\footnotetext{
${ }^{3}$ Tradução livre.

4 "For a long time the social philosophy of Jürgen Habermas and contemporary feminism evolved in mutual indifference. When modern feminists did occasionally turn their attention in his direction, the judgement

was usually negative and sometimes even scathing". "Por muito tempo a filosofia social de Jürgen Habermas e o feminismo contemporâneo se envolveram em mútuas diferenças. Quando feministas modernas ocasionalmente voltaram a atenção à sua direção, o julgamento foi normalmente negativo e algumas vezes até mordaz". (JOHNSON 2001, 39).

5 Tradução livre.
}

${ }^{6}$ Esse tópico será desenvolvido em maiores detalhes posteriormente. 
Nessa premissa, portanto, propomos uma análise dos principais aspectos do agir comunicativo proposto por Habermas a partir de premissas feministas, na tentativa de centralizar questões de gênero na teoria habermasiana. Para tanto, primeiramente apresentamos uma leitura das noções das esferas do agir comunicativo e da diferenciação entre público e privado em Habermas através da crítica elaborada por Nancy Fraser. Em um segundo momento, discutimos as perspectivas de poder e de razão, demonstrando sua problematização a partir da visão feminista radical de Catherine MacKinnon.

\section{FEMINISMO ENTRE ESFERAS DE AÇÃO SOCIAL: A TEORIA CRÍTICA FEMINISTA DE NANCY FRASER}

O slogan "o privado é político" é, desde o pós Segunda Guerra Mundial, um mote básico movimento feminista. Esta chamada feminista sublinha que a subordinação feminina à forma masculina de poder político e econômico na sociedade contemporânea não é mantida apenas no âmbito das instituições e na esfera pública, mas que a constituição nuclear familiar contém as mesmas dimensões que permitem ao homem desigualar, subordinar, explorar e silenciar a ação política e social feminina, e mais que isso, fundamentam a opressão e subordinação pública. Para muitas teóricas feministas, portanto, a situação da mulher como cidadã de segunda classe perpassa qualquer separação sistemática entre as esferas de atuação, estando presente de modo generalizado nas sociedades contemporâneas. Como MacKinnon $(1987,93)$ aponta, tanto a sexualidade como o gênero não são restritos e não competem apenas a esfera privada, mas à sociedade em geral. Essas distinções entre público e privado, contudo, são centrais em Habermas.

Segundo Fraser $(1995,34)$, uma crítica feminista da teoria habermasiana precisa da análise de conceitos centrais: (i) sistema e mundo da vida (lifeworld); (ii) distinção entre reprodução material e simbólica; e (iii) dimensões da esfera pública e privada. Fraser argumenta que para Habermas “sistemas" são formas em que indivíduos se coordenam um com o outro, com consequências conectadas, i. e., interligadas, de decisões tomadas a partir de auto interesse. Nessa premissa, o sistema mais relevante para a análise de Habermas é o aparato jurídico-administrativo, e sua conexão com o aparato econômico. Estes dois sistemas, quando vistos de forma correlacionada formam a principal arquitetura do Estado moderno. Por outro lado, a esfera da vida social age de acordo com seu próprio mecanismo regulatório e lógico, o que ocorre pela soma das relações e interações entre as pessoas de determinada comunidade. Portanto, o mundo da vida (lifeworld) seria a socialização integrada de ações de determinado contexto.

Contextos de ação socialmente integrados são aqueles em que os diferentes agentes coordenam suas ações com o outro por referência a algum tipo de consenso intersubjetivo explícito ou implícito sobre normas, valores e fins, consenso baseado em um discurso linguístico e na interpretação. Contextos de ação integrados ao sistema, por outro lado, são aqueles em que as ações dos diferentes agentes são coordenadas com os outros pelo entrelaçamento funcional de consequências não intencionais, enquanto cada ação individual é determinada pelo auto interesse, pelo cálculo utilitário de maximização normalmente entretidos nos idiomas, ou como Habermas diz, na "mídia" do dinheiro e do poder (FRASER $1995,34)^{7}$.

Fraser critica nessa concepção de Habermas a ideia de que dinheiro e poder servem como cálculo utilitário apenas no âmbito jurídico-administrativo, como se as dinâmicas de subordinação que se estabelecem nessa esfera fossem de alguma forma diferentes das dinâmicas em outros contextos sociais, especialmente no 
familiar. Assim como, afirma que "a grupos socialmente subordinados normalmente falta o acesso igualitário aos meios materiais para participação igualitária" (FRASER 1990, 64), tanto na esfera administrativa quanto na esfera do mundo da vida. Fraser argumenta, portanto, que em sociedades complexas as dinâmicas de autonomia, estratégias e consenso são mais variadas, e podem ocorrer tanto no âmbito administrativo quanto no social. Segundo Johnson $(2001,42)$, nessa mesma premissa, Habermas continua ignorando o contexto de gênero que informa a concepção da sociedade dividida entre certos domínios de modos apropriados de integração. Essas premissas também podem ser criticadas através da perspectiva do feminismo radical. MacKinnon $(1987,2)$, por exemplo, ressalta que o próprio conceito masculinizado (no sentido de dominação por parte do homem) de dinheiro, poder e maximização de interesses individuais, consegue modificar fundamentalmente as relações entre homens desse contexto social, pois como já mencionado acima, para MacKinnon a forma com a qual a mulher consegue se integrar nesses sistemas políticos - ou jurídicos-administrativos em termos habermasianos - é através do sexo. Nesse sentido, para MacKinnon $(1987,6)$ a "sexualidade aparece como a dinâmica interativa de gênero como uma desigualdade". A resposta que Fraser dá para esta questão é desenhar as diferenças de níveis e proporções nestas interações.

Por conseguinte, parece justo prosseguir deste primeiro conceito habermasiano para o segundo ponto criticado por Fraser. Na Teoria do Agir Comunicativo, Habermas faz a diferenciação entre produção material e produção simbólica. Habermas afirma que uma sociedade necessita se desenvolver materialmente através da regulação de mecanismos de trocas de grupos de indivíduos com não humanos, com o ambiente externo (físico) e outros sistemas sociais, reproduzindo, nesse sentido, o que Habermas chama de "trabalho social". Por outro lado, sociedades também devem desenvolver reproduções simbólicas deles mesmos que transmitem para futuras gerações ou novos membros linguagem e normas que constituem a identidade social ${ }^{8}$.

É claro que em sociedades marcadas pela desigualdade de gênero, a participação feminina nessas dinâmicas de produção precisa ser analisada de forma social e culturalmente constituída. Grande parte das produções simbólicas é constituída por funções não pagas dentro de sociedades capitalistas, como por exemplo, o cuidado de crianças e idosos, que normalmente fica sob a responsabilidade da figura feminina. Habermas afirma que a reprodução simbólica da identidade cultural é essencial para sobrevivência do ethos social. Contudo, a crítica de Fraser é no sentido de que a possibilidade de uma perspectiva naturalista, isto é, expectativa de performance pautada por diferenças biológicas, legitima determinadas subordinações de mulheres. O movimento feminista apontou como sociedades patriarcais utilizam dessas premissas biológicas como maternidade e determinações arbitrárias do "comportamento feminino" para aprisionar as mulheres ao âmbito doméstico sem acesso à esfera pública e política, ou seja, separam mulheres em outra esfera, subordinadas.

\footnotetext{
Assim, de acordo com Habermas, em sociedades capitalistas as atividades e práticas que constituem a esfera de trabalho remunerado contam como atividades de reprodução material, já que, nessa visão, elas são "trabalho social" e servem a função de reprodução material. Por um lado, as atividades e práticas, que na nossa sociedade são realizadas sem remuneração por mulheres na esfera doméstica - podemos chama-las de "trabalho feminino não remunerado de criação de crianças" - contam como atividades de reprodução simbólica já que, na visão de Habermas, elas servem à socialização e à função de reprodução simbólica (FRASER 1995, 33) .
}

\footnotetext{
8 "Habermas afirma que a reprodução material engloba o que ele chama de "trabalho social” [...] Reprodução simbólica, por outro lado, engloba a socialização dos jovens, a consolidação da solidariedade de grupo e a transmissão e extensão de atividades culturais" (FRASER 1995, 33). Tradução livre.
} 
Além dessa visão pouco cuidadosa da forma como estas esferas de reproduções são determinadas em função de noções de gênero, Fraser ainda argumenta que reproduções materiais também são responsáveis pela perpetuação simbólica do ethos de determinada sociedade. Por exemplo, segundo Fraser, a produção material de objetos e de alimentos das sociedades faz parte daquilo que constitui sua representação simbólica e ao mesmo tempo "reproduz identidades sociais" $(1995,33)$. Uma perspectiva feminista, portanto, nega afirmações de cunho naturalista em análises da sociedade contemporânea, algo que parece constar de maneira acrítica na perspectiva habermasiana.

Nesse sentido, essa crítica da Fraser reforça a centralidade da categoria de gênero na perspectiva feminista, uma vez que a submissão da mulher a estruturas fundamentalmente sexistas que favorecem uma funcionalidade artificialmente relacionada à figura masculina determinam uma posição secundária à mulher nessas sociedades. Como apontado por MacKinnon $(1987,7)$, há um problema fundamental em considerar a desigualdades dos sexos pautados por "diferenças", porque a "desigualdade dos sexos é definida socialmente como o gozo da própria sexualidade, desigualdade de gênero parece consensual" ${ }^{10}$. O ponto de MacKinnon, e de certa forma o ponto de Fraser, é salientar que gêneros não são estabelecidos socialmente apenas como diferença, mas sim como formas hierárquicas de poder, tanto em âmbito jurídico-administrativo perpetuado por normas formais e sociais, quanto na esfera doméstica.

Feministas demonstraram através da análise empírica da tomada de decisões familiar contemporânea [...] que famílias são permeadas pela mídia do poder e do dinheiro, nos termos de Habermas. Elas são sítios de cálculos egocêntricos, estratégicos e instrumentais assim como espaços de trocas geralmente exploradoras de serviços, trabalho, dinheiro e sexo, sem mencionar locais frequentes de coerção e violência [...]. Finalmente, ele falha em destacar o fato de que em ambas as esferas mulheres são subordinadas a homens (FRASER 1995, 37) ${ }^{11}$.

Em "Entre facticidade e validade", Habermas argumenta que a perspectiva do Sistema de Direitos visa assegurar autonomia, ou como afirma "autonomia pública e privada das pessoas privadas", buscando legitimar os procedimentos jurídicos como uma esfera para "configuração política autônoma dos direitos fundamentais" (HABERMAS 1997, 148). Além disso, Habermas sugere que a autonomia privada dos indivíduos pode ser realizada e de certa forma substituída por uma autonomia de participação em processos de sociais. Habermas demonstra também uma preocupação com a efetivação de direitos estabelecidos através do agir comunicativo de fato, uma vez que a positivação de normas jurídicas produzidas legitimamente "não pode ser dissociada da autonomia pública dos cidadãos” (HABERMAS 197, 159).

Os problemas de igualdade de tratamento entre homem e mulher levam a tomar consciência de que as pretendidas autorizações não podem ser entendidas apenas como favores dispensados pelo Estado social no sentido de uma participação justa. Os direitos podem autorizar as mulheres a uma configuração autônoma e privada da vida, porém somente na medida em que eles possibilitem, ao mesmo tempo, uma participação, em igualdade de direitos, na prática de autodeterminação de cidadãos, pois somente os envolvidos são capazes de esclarecer pontos de vista relevantes em termos de igualdade e de desigualdades (HABERMAS 1997, 160).

Apesar de Habermas fazer considerações acerca da efetividade de ações praticadas na esfera pública,

\footnotetext{
${ }^{10}$ Tradução livre.

${ }^{11}$ Tradução livre.
} 
ele não parece abandonar a dicotomia que estabeleceu entre domínios públicos e privados. Habermas ainda coloca as demandas do movimento feminista enquanto fundamentalmente emancipatórias, principalmente, quanto a questões de igualdade de tratamento jurídico. Esses dois aspectos, contudo, precisam de um olhar mais crítico do ponto de vista do feminismo.

Na "Teoria do Agir Comunicativo", por sua vez, Habermas estabelece uma diferenciação entre esfera pública e esfera privada. O autor propõe uma visão "Inter institucionalizada" das relações entre as várias esferas do mundo da vida (lifeworld), que dispõe de sistemas-integrados de ação como o estatal e o econômico com respeito ao âmbito do contexto de interações sociais. Entretanto, para Habermas, o mundo da vida (lifeworld) é dividida em duas esferas, a saber, pública e privada. Na esfera privada, Habermas considera estritamente o núcleo familiar, que é conectado enquanto agente ao sistema econômico. Já a esfera pública é o espaço de participação política, debates e formação de opinião, que é, portanto, conectado com ao espaço jurídico-administrativo. Nesse sentido, Habermas afirma:

Os núcleos privados do mundo da vida [lifeworld], caracterizados pela intimidade, portanto protegidos publicamente da publicidade, estruturam encontros entre parentes, amigos, conhecidos, etc., e entrelaçam as biografias das pessoas conhecidas. A esfera pública mantém uma relação complementar com essa esfera privada, a partir da qual é recrutado o público titular da esfera pública. No seu conjunto, o mundo da vida forma uma rede de ações comunicativas. Sob o ângulo da coordenação da ação, seu componente social consiste na totalidade de relações interpessoais ordenadas legitimamente. (HABERMAS 1997, 86)

Habermas falha em tematizar a questão de gênero nessas esferas. Segundo Fraser, em ambos os contextos, da economia privada no sistema jurídico-administrativo e o privado da família no sistema mundo da vida, há uma relação mediada por papéis de trabalhadores e consumidores, funções que tem gêneros pré-estabelecidos (FRASER 1995, 42). A própria função familiar argumentada por Habermas, quando posta sob uma perspectiva feminista, mantém uma relação não apenas de interlocução e conectividade entre sistemas, mas uma relação hierárquica de dominação masculina. Nas palavras de Adiche (2015):

Já que pertenço ao sexo feminino, espera-se que almeje me casar. Espera-se que faça minhas escolhas levando em conta que o casamento é a coisa mais importante do mundo. O casamento pode ser bom, uma fonte de felicidade, amor e apoio mútuo. Mas por que ensinamos as meninas a aspirar ao casamento, mas não fazemos o mesmo com os meninos?

Nessa premissa, o núcleo privado da família não pode ser considerado como um sistema natural estabelecido pela socialização, mas ao contrário, como socialização sistemática da subordinação feminina.

Em segundo lugar, a própria divisão entre esferas é uma concepção de sociedade e política obsoleta para as teorias feministas (e aqui observamos uma clara aproximação entre Fraser e MacKinnon). Apesar de Habermas ter avançado na discussão privado-público ao demonstrar uma "relação da totalidade com o mundo da vida" (HABERMAS 1997, 86), ainda assim não é o caso de uma correlação, ou de uma relação horizontalizada, mas sim da existência de uma mesma estrutura e hierarquia, apenas em nível diferente. Uma vez que a mulher é subordinada, silenciada, sexualizada, tornada invisível, e tratada como cidadã de segunda classe em todos os sistemas, tanto na esfera pública quanto privada, não há como estabelecer uma diferenciação entre esferas, quando a diferenciação está alicerçada de maneira fundamental e primária no sexo. 
Pesquisadoras feministas tem documentado uma síndrome que muitos de nós temos observado em encontros na faculdade e outros corpos deliberativos com sexos mistos: homens tendem a interromper mulheres mais que mulheres interrompem homens, homens também costumam falar mais que mulheres, falando mais vezes e mais longamente, e intervenções de mulheres são mais frequentemente ignoradas ou não respondidas do que a dos homens. ${ }^{12}$ (FRASER 1990, 64)

Considerar a desigualdade entre sexos como diferenciação parece por si só ser problemática ao feminismo: como aponta MacKinnon $(1987,8)$ "a desigualdade vem primeiro, diferenças vem depois" ${ }^{13}$. Para a autora, a relação estabelecida entre os gêneros é posta hierarquicamente, e por isso a submissão sistemática da mulher não pode ser tratada como diferença de gênero, mas sim como afirmação de status de poder baseada “em quem pode fazer o que com quem"14" (MACKINNON 1987, 8).

A chamada primeira onda do feminismo, situada historicamente entre o fim do século XIX e o início do século XX, apresentava reinvindicações que versavam especificamente sobre a autonomia privada no domínio público, como o direito ao voto e à propriedade, por exemplo. Contudo, após a Segunda Guerra Mundial, com a emergência da chamada segunda onda do movimento feminista, esse movimento social uniu a noções de público e privado através da ideia de que o privado também era permeado por dimensões e dinâmicas políticas. Esse argumento não apenas fortalecia politicamente a mulher que ainda permanecia (e permanece) socialmente condicionada e restrita ao âmbito doméstico, mas também sublinhava o silenciamento de dinâmicas que além de subordinar a mulher, a violenta física e psicologicamente.

O Liberalismo tem sido subversivo para nós no sentido em que ele sinaliza que nós temos a audácia de nos comparar com os homens, de nos medir através de padrões e termos masculinos. Nós criticamos a nossa exclusão das atividades masculinas. Mas o Liberalismo nos limita de uma maneira que o feminismo não o faz. Nós também criticamos as atividades do sexo masculino para o ponto de vista das mulheres, do ponto de vista da nossa experiência social como mulheres. O feminismo visa capacitar as mulheres em nossos próprios termos. Para valorizar o que as mulheres sempre fizeram, bem como para permitir-nos fazer tudo o resto. Buscamos não só para ser valorizado como quem somos, mas para ter acesso ao processo de definição de valor em si. Desta forma, a nossa demanda de acesso torna-se uma demanda por mudanças (MACKINNON 1987, 22) ${ }^{15}$.

A progressão do movimento feminista parece deixar claro que a mulher nunca teve uma esfera privada própria, mas sempre atuou como participante submissa da esfera privada dos homens. O feminismo enquanto movimento social saiu às ruas com corpos de gênero específico e contextualizado, tornando público às dinâmicas privadas de objetificação. Nesse sentido, a práxis feminista transforma o corpo, a sexualidade, o desejo e a opinião da mulher em elementos públicos de transgressão dos sistemas patriarcais. Nesse sentido, é interessante notar a aproximação da crítica de Fraser com os apontamentos feministas de MacKinnon. Ainda que situadas em campos diferentes dentro da teoria política feminista, ambas autoras parecem compartilhar agravos semelhantes em suas avaliações da obra da Habermas - a saber, que igualdade social não é posta como uma condição necessária para participação párea na esfera pública (FRASER 1990, 65). Tal aproximação se torna ainda mais explicita ao analisarmos a crítica radical elaborada por MacKinnon.

\footnotetext{
12 Tradução livre.

13 Tradução livre.

14 Tradução livre.

15 Tradução livre.
} 


\title{
A CRÍTICA RADICAL A UM ESTADO PATRIARCAL: A TEORIA DO ESTADO FEMINISTA DE CATHERINE MACKINNON
}

Em "Entre facticidade e validade", Habermas tenta se posicionar a favor do feminismo liberal, uma vez que reconhece mais demandas por pautas que ele chama de emancipatórias de "igualdade de tratamento jurídico" (HABERMAS 1997, 160). Além disto, esse autor afirma que reivindicações de conteúdo liberal pretendem "uma inclusão maior das mulheres nos sistemas de ação social" (HABERMAS 1997, 161), ou seja, oferece uma perspectiva crítica do papel da mulher nos sistemas jurídico-administrativo e no do mundo da vida (lifeworld). Nessa premissa, a manifestação e reivindicação pela igualdade de direitos e de igualdade de fatos entre homens e mulheres, segundo Habermas, devem ocorrer dentro destes sistemas que integram a vida social e política dos cidadãos.

\begin{abstract}
A ideia de uma sociedade justa implica a promessa de emancipação e dignidade humana. Pois o aspecto distributivo da igualdade de status e de tratamento, garantido pelo direito, resulta do sentido universalista do direito, que deve garantir a liberdade e integridade de cada um. Pois isso, na sua respectiva comunidade jurídica, ninguém é livre enquanto sua liberdade implicar a opressão do outro. (HABERMAS 1997, 158).
\end{abstract}

Aqui, Habermas reconhece e enfatiza a dificuldade de concretização entre igualdades de direito e igualdade de fato; assim como apoia medidas compensatórias que impeçam que "desvantagens específicas ao sexo se acumulem" (HABERMAS 1997, 163). A proposta de Habermas, para reintegrar essa separação entre direitos e fatos é uma reflexão dialética entre estes, isto é, eles precisam ser articulados a partir dos pontos de vista divergentes, institucionalmente, através da comparação e fundamentação de argumentos (HABERMAS 1997, 167). Para Habermas, portanto, esse diálogo entre pontos de vista deve ocorrem "pelos próprios afetados em discurso público" (HABERMAS 1997, 167).

Para se colocar a favor da argumentação pública das demandas feministas, Habermas critica algumas premissas do feminismo radical, especialmente algumas questões colocadas por Catherine MacKinnon em seu livro "Toward a feminist theory of State", de 1991. Em primeiro lugar, Habermas questiona as críticas de MacKinnon à forma que o discurso liberal recorrentemente coloca a relação entre homens e mulheres em termos de desigualdade (HABERMAS 1997, 164). Para MacKinnon (1987), as relações são pautadas por gêneros já classificados e submetidos a um sistema hierárquico de poder através do sexo. Nesse sentido, o feminismo radical faz uma crítica aos estereótipos e à caracterização de identidade dos sexos através da normatização e naturalização dos seus propósitos sociais. Para MacKinnon, contudo, quando falamos de diferenças entre gêneros dentro de um sistema patriarcal, estamos tomando como norte doutrinas estabelecidas pela figura masculina, que não apenas colocaram-se diferentes em relação à situação da mulher, mas enquanto posição de dominação da mulher. Nessa premissa, ser igual é ser homem (MACKINNON 1987, 32). E, portanto, a mulher nunca tem a possibilidade de definir a si própria enquanto sujeito.

A filosofia subjacente à abordagem da diferença é que o sexo é a diferença, uma divisão, uma distinção sob a qual encontra-se um estrato de similaridade humanamente condicionado. O impulso moral do ramo de similaridade da doutrina é fazer regras normativas em conformidade com esta realidade empírica, concedendo às mulheres acesso ao que os homens têm: na medida em que as mulheres não são diferentes do que os homens, nós merecemos o que eles têm (MACKINNON 1987, 33) ${ }^{16}$. 
Habermas ainda acusa o feminismo radical de sustentar uma generalização de uma categoria, a saber, das mulheres, baseada em pressuposições de "diferenças e de situações de vida" (HABERMAS 1997, 167). Segundo Habermas, essa generalização de experiências de vida não condiz com o contexto social interseccional, pois questões específicas como classe, cor, nacionalidade, sexualidade, etc., contam como parte da constituição do sujeito e sua condição interligada aos sistemas jurídico-administrativo e do mundo das coisas.

Provavelmente, considerando todas as vertentes feministas, o feminismo radical seja o que afirma mais contundentemente sobre uma divisão real e objetiva da sociedade baseada apenas num fator tão fortuito quanto o gênero. A própria MacKinnon $(1991,30)$ afirma que a falha do feminismo marxista e do feminismo liberal é colocar o problema de gênero como parte do plano político e estrutural, quando na verdade, o próprio sistema (tanto socialista quanto capitalista) já é estruturado através de hierarquias de gêneros plenamente constituídas, em que "a questão da mulher é sempre reduzida a alguma outra questão, ao invés de ser visto como a questão, que chama por uma análise nos seus próprios termos ${ }^{17 "}$ (MACKINNON 1991, 8).

\begin{abstract}
Eles argumentam que a análise da sociedade em termos de sexo ignora a primazia da classe e atenua a divisão de classes entre as mulheres, dividindo o proletariado. Demandas feministas, alega-se, poderiam ser totalmente satisfeitas dentro do capitalismo, de modo que suas atividades minam e desviam o esforço para a mudança de base. Os esforços para eliminar barreiras à personalidade da mulher - argumentos para acesso a mudanças de vida, sem distinção de sexo - são vistos como liberais e individualistas. $\mathrm{O}$ que quer que as mulheres têm em comum é considerado a ser baseada na natureza, não na sociedade. (MACKINNON 1991, 5) ${ }^{18}$.
\end{abstract}

Nesse sentido, para MacKinnon (1991, 8), qualquer mulher independentemente de classe, cor, etnia, orientação sexual, etc., consegue perceber dinâmicas de dominação masculina, submissão e objetificação feminina em suas sociedades. A generalização criticada por Habermas, portanto, é totalmente assumida e defendida pela MacKinnon enquanto dinâmicas políticas básicas que são necessariamente verdadeiras e sexuais, além de constitutivas das sociedades contemporâneas. Dessa forma, a hierarquia dos gêneros se dá através da sexualidade per se, uma vez que "a dominação masculina é sexual” (MACKINNON 1991, 127).

\begin{abstract}
A teoria da sexualidade torna-se metodologicamente feminista, ou seja, feminista no sentido pós-marxista, na medida em que trata a sexualidade como uma construção social para o poder masculino: definida por homens, forçada sobre as mulheres, e constitutiva do significado de gênero. Tal abordagem centra o feminismo na perspectiva da subordinação das mulheres aos homens como ela identifica como o sexo - ou seja, a sexualidade de dominação e submissão - tão crucial, como um direito fundamental, como em algum nível definido nesse processo. A teoria feminista torna-se um projeto de analisar essa situação, a fim de mudá-la (MACKINNON 1991, 128) ${ }^{19}$.
\end{abstract}

Ao utilizar as políticas feministas como exemplos de "dialéticas de fato e direito" (HABERMAS 1997, 147) e ao considerar uma análise de Estado pautada pela hierarquia dos sexos uma "glorificação da natureza feminina" (HABERMAS 1997, 167), Habermas parece estar justamente incluindo oportunamente a questão de gênero como um exemplo da eficácia do agir comunicativo nos movimentos sociais, o que implica que a questão da mulher e da sua posição de subordinação social e política pode ser nivelada na mesma medida que qualquer outra demanda social, e, portanto, discutida amplamente na esfera pública. Essa utilização do feminismo enquanto apenas mais um patamar da desigualdade social, entretanto, é justamente parte da crítica 
de MacKinnon, uma vez que a autora nega que a questão da mulher possa ser colocada em termos de diferenças e desigualdade, mas sim, em termos específicos de submissão necessariamente feminina, e dominação necessariamente masculina, plenamente estrutural e formativa de todas as camadas políticas (isto é, tanto no jurídico-administrativo quanto no mundo da vida). Nesse sentido, para MacKinnon a hierarquização dos sexos é a forma primeira ou original das desigualdades sociais, e relegar esse problema a uma dinâmica de resolução dialética significa ignorar (i) a primazia dessa subordinação na constituição de nossas sociedades, contaminando todas as suas esferas, e (ii) relegar direitos fundamentais à discussão pública.

Habermas reconhece a deficiência do direito liberal ao assumir um aspecto "distributivo da igualdade de status e de tratamento", pois uma "distribuição igual de direitos", não garante a liberdade de acesso a estes direitos, "ninguém é livre enquanto sua liberdade implicar na opressão do outro" (HABERMAS 1997, 159). Nessa premissa, Habermas parece centralizar as demandas feministas enquanto demandas emancipatórias que devem garantir a "autonomia privada de sujeitos privados" (HABERMAS 1997, 169) que possam ser efetivados, e que só podem acontecer no momento em que se fortalecer "a posição das mulheres na esfera pública política, nas quais é possível esclarecer os aspectos relevantes para uma posição de igualdade" (HABERMAS 1997, 169).

As críticas de MacKinnon à constituição de um procedimentalismo liberal e da própria noção de autonomia da mulher nessas esferas, contudo, não são respondidas por Habermas. Para MacKinnon, tanto autonomia quanto permissividade é problemático para mulheres dentro de um sistema político e de direito formado numa hierarquia masculina, "como se a mulher sob uma supremacia masculina tivesse poder para [...] como se ‘negociação' fosse uma forma de liberdade” (MACKINNON 1991, 135).

Na proposta de MacKinnon fica evidente que não há como desassociar de uma proposta feminista a relação estrita entre política e sexualidade, por isso o papel discursivo e da própria sexualidade da mulher neste cenário impossibilita em diversos níveis uma posição de autonomia. Afinal, como podemos pensar na autonomia da mulher no cerne de estruturas fundamentalmente masculinizadas que fazem a socialização da mulher ser profundamente sexualizada (para satisfazer interesses dos homens) e objetificada? Seguindo essa premissa, MacKinnon afirma que a dominação do sistema masculino é prazer e "mulheres, as quais não são dadas escolha, são objetificadas; ou, ao invés, "o objeto é permitido a desejar, se ela desejar ser um objeto"” (MACKINNON 1991, 140).

\footnotetext{
Ser objetificada sexualmente significa ter um significado social imposto sobre o seu ser, que lhe define como para ser usada sexualmente, de acordo com seus usos desejados e, em seguida, usando-a dessa maneira. Fazer isso é o sexo no sistema masculino. [...]. Não há nenhuma essência irredutível, não "apenas sexo". Se o sexo é uma construção social do sexismo, os homens têm relações sexuais com a sua imagem de uma mulher (MACKINNON 1991, 140).
}

Esse déficit de autonomia da mulher em uma sociedade estruturalmente masculinizada é central para a argumentação antipornografia. Tanto MacKinnon quanto Andrea Dworkin são pioneiras e centrais para o movimento antipornografia nos Estados Unidos. Para elas, a pornografia tem o papel de sexualizar, e neste sentido, tornar prazerosa, a própria desigualdade dos sexos $(1991,143)$. MacKinnon $(1991,144)$ afirma que na pornografia grande parte dos comportamentos que a sociedade costuma condenar, como por exemplo, humilhação, tortura, dor, e desigualdade, são postos de forma naturalizada e aceitável enquanto sexo. Na pornografia, e no sexo em geral (que tem uma influência direta entre um e outro), extrapola-se todas as barreiras de opressões da dominação masculina, onde é aceitável a violência contra a mulher como forma de expressão 
da hierarquia de gênero (MACKINNON 1991, 143), ou como sugere o título de Dworkin (1989), "men possessing women".

\begin{abstract}
A pornografia permite que os homens tenham o que quiserem sexualmente. É a sua "verdade sobre sexo". Ela conecta a centralidade da objetificação visual tanto à excitação e aos modelos masculinos de verificação de conhecimento, objetividade com objetivação. [...]. Cada violação de mulheres - estupro, violência física, prostituição, abuso sexual, assédio sexual - é feita a sexualidade, feita sexy, divertida e libertadora da verdadeira natureza das mulheres na pornografia. [...]. Qualquer coisa que as mulheres têm reivindicado como suas - a maternidade, atletismo, trabalhos tradicionais dos homens, o lesbianismo, o feminismo - é feito especificamente sexy, perigoso, provocante, castigado, feita para homens na pornografia (MACKINNON 1991, 138).
\end{abstract}

MacKinnon $(1991,136)$ ainda salienta que a diferença fundamental entre estupro e o sexo é o consentimento, e que parte da dominação masculina sobre as mulheres se dá através da sexualização da escolha e do consentimento, em que o "forçado" à mulher torna-se desejado e legitimado. Essas expressões são, para MacKinnon $(1991,159)$, centradas na sexualidade masculina, uma vez que a mulher não tem escolha na posição da sua própria identidade sexual, e não consegue confrontar as relações sociais e com o Estado em seus próprios termos. O problema de uma regulamentação da pornografia pelo Estado, portanto, é que "as leis veem e tratam as mulheres do modo como os homens veem e tratam as mulheres" (MACKINNON 1991, 162).

A lei antipornografia proposta por MacKinnon e Dworkin (1997), tem como objetivo modificar a abordagem legal às questões de gênero, uma vez que "as leis do direito civil são uma força opositora à mudança". MacKinnon $(1991,164)$ afirma que tanto as tradições legais da "liberdade positiva" quanto da "liberdade negativa" são expressões de Estados com princípios de desigualdades sistemáticas que naturalizam e reafirmam opressões sociais, anteriores as leis, que subordinam e oprimem a mulher. Nessa premissa, a proposta de MacKinnon implica que para alterar a realidade de desigualdade entre homens e mulheres é necessário "eliminar a subordinação das mulheres como padrão" (MACKINNON 1991, 5). Essa lei antipornografia abandona as questões morais e privadas da pornografia em favor das questões de ordem de segurança pública, segurança social e igualdade civil, nas quais são dadas o recurso para denunciar e provar os danos das violências de gênero sofridas.

\footnotetext{
A liberdade negativa dá a uma pessoa o direito a ser "deixada fazer ou ser o que [ela] é capaz de fazer ou ser, sem a interferência de outra pessoa". O estado que exerce este valor promove a liberdade quando não intervém no status quo social. Liberdade positiva, a liberdade de fazer, em vez de manter-se de o que está sendo feito, mediante a distinção, dá a uma pessoa o direito de "controle ou determina ... alguém para fazer, ou seja, este em vez de isso'. Se um grupo é socialmente concedido a liberdade positiva para fazer o que quiser para outro grupo, para determinar o que o segundo grupo vai ser e fazer isso em vez do que aquilo, nenhuma quantidade de liberdade negativa garantida legalmente ao segundo grupo irá torná-lo igual ao primeiro (MACKINNON 1991, 164)
}

Nesse sentido, fica claro que para MacKinnon a opressão de gênero, i.e., das mulheres, ocorre indistintamente no jurídico-administrativo e no mundo da vida (lifeword). Portanto, assim como Fraser, essa autora nega uma divisão entre esferas pública e privada. Nesse sentido, MacKinnon $(1991,191)$ afirma que feministas "confrontam o fato de que mulher não tem privacidade para perder ou para garantir" (MACKINNON 1991, 191), e que a divisão entre esferas públicas e privadas garante apenas um espaço seguro e inquestionável (ou seja, a esfera privada) para a dominação masculina. Direito privado é um privilégio masculino, uma vez que é garantido sem que antes a igualdade social seja um requisito, "a esfera privada, que confina e separa as mulheres, é, portanto, uma esfera política, um campo comum da desigualdade de mulheres" (MACKINNON 
1991, 193).

Apesar de avançarem propostas diferentes de teorias feministas, situando-se em campos conceituais diversos, tanto para Fraser quanto para MacKinnon a teoria habermasiana não consegue oferecer uma saída para a opressão de gênero sofrida pelas mulheres nas sociedades contemporâneas. Parte dessa coesão na crítica a Habermas se dá pela divisão assumida pelo autor entre os espaços públicos e privados que cristaliza uma esfera de privilégio para homens, e ignora a premissa feminista da indistinção entre esses dois espaços, ou seja, a noção de que o privado é público, indistintamente. Além disso, Habermas compreende a situação de subordinação das mulheres como mais uma área de desigualdade social, com demandas ao nível de qualquer outro movimento social, e não uma desigualdade fundadora, como as autoras analisadas nesse artigo a entendem. Nesse sentido, qualquer proposta política feminista, para Habermas, parece ter que se submeter, necessariamente, ao procedimentalismo habermasiano que se dá em estruturas especificamente dominadas pela figura masculina. Para autoras como Fraser e MacKinnon, proposta não constitui uma alternativa viável, tendo em vista que possibilita a reprodução e consolidação de estruturas profundamente sexistas.

\section{CONSIDERAÇÕES FINAIS}

A Teoria do Agir Comunicativo de Habermas almeja alcançar uma sociedade interligada pelos seus aspectos jurídico-administrativos e sociais através da ação comunicativa e da socialização material e simbólica de reproduções de sociedades modernas. Apesar de reconhecerem a relevância das temáticas tratadas por Habermas para as teorias feministas, muitas teóricas criticaram a falta de atenção dada por Habermas às problemáticas de gênero nas sociedades contemporâneas. Nesse sentido, feministas como Fraser e MacKinnon compreendem que tanto os sistemas apresentados por Habermas quanto as formas de interligar esses sistemas não são suficientes para desafiar a normatividade sexista das instituições que perpassam essas esferas. A participação das mulheres no agir comunicativo deve ser central, afinal Habermas mesmo colocou como condições de sua teoria a igualdade e liberdade dos agentes. Entretanto, Habermas falha em apresentar uma visão estrutural-sistemática mais crítica quanto às limitações e considerações acerca das questões de desigualdade de gênero, deixando inertes conceitos problemáticos como a família, o Estado, o sistema de direitos, e a diferenciação entre público e privado. Apesar de num segundo momento, em "Entre facticidade e validade", Habermas tenha retomado uma perspectiva preocupada com a condição da mulher, essa desigualdade que estrutura todo o sistema e condiciona a agencia da mulher foi posta como contingente, sendo, portanto, incapaz de responder satisfatoriamente algumas críticas e apontamentos feministas pontuais.

Habermas acertou em fazer uma interlocução entre discursos públicos e feminismo, mas, por outro lado, há pontos controversos entre a teoria habermasiana e propostas feministas e, nesse sentido, acreditamos que é a ideia de que "os aspectos sob os quais a diferença de experiências e situações de vida de mulheres e homens se tornaram relevantes para um aproveitamento igualitário de liberdades de ações subjetivas, têm que ser esclarecidas através de discussões públicas" e "pelos próprios afetados em discurso público" (HABERMAS 1997, 167). Primeiramente, a própria definição sobre quem são os "afetados" pelos discursos públicos é recorrentemente problemático para o movimento feminista. Por exemplo, direitos reprodutivos concernem da mesma forma tanto para homens quanto para mulheres que justifique um espaço de fala igual entre estes? Nessa premissa, mais uma vez, um olhar atento a problemas de gênero problematiza o a distinção comum entre público e privado, enfatizando a autonomia da mulher, inclusive para ter os espaços de decisões sem a participação hierárquica do homem. 
Num contextos de inferioridade representativa de gênero na política, evidenciando a dificuldade do acesso da mulher a determinados sistemas que são fundamentalmente ocupados por homens, o agir comunicativo antes de se tornar um espaço consciente e democrático, torna-se um espaço onde a mulher necessita barganhar com os sistemas patriarcais direitos humanos básicos e, se consideramos, conforme sugere MacKinnon, o poder social colocado por hierarquia de sexo, os termos desta barganha pública parecem permanecer desfavorecendo o discurso feminista. Essa condição do discurso da mulher, contudo, não exclui a necessidade performativa do feminismo enquanto movimento social de espaços públicos. Como bem colocado por Fraser, uma Teoria Crítica Feminista tem questões de gênero centralizado em suas análises políticas, e não como contingências sociais. Desta forma, não apenas um argumento, mas um sexo, um corpo, uma sexualidade, torna-se agente do agir comunicativo, e além das discussões públicas, a ocupação desses espaços de fala é fundamental para que o objetivo mais primário do feminismo seja realizado: o tratamento das mulheres como seres humanos.

\section{REFERÊNCIAS}

ADICHIE, C. N. 2015. Sejamos Todos Feministas. São Paulo: Cia. Das Letras (Edição Eletrônica).

ALLEN, A. 2012. The unforced force of the better argument: reason and power in Habermas. Constellations Vol. 19, No 3, pp. 353-368.

BENHABIB, S. e CORNELL, D. 1987. Feminism as critique. Minneapolis: University of Minnesota DWORKIN, A. 1989. Pornography: Men Possessing Women. New York: Plume.

FRASER, N. 1995. What's Critical about Critical Theory? The Case of Habermas and Gender. In: MEEHAN, J. 1995. Feminists read Habermas: Gendering the Subject of Discourse. New York: Routledge.

FRASER, N. 1990. Rethinking the Public Sphere: contribution to the critique of actually existing democracy. In: Social Text. No. 25/26 (1990), pp. 56-80. Duke University Press.

HABERMAS, J. 1997. Direito e democracia: entre facticidade e validade. Volume II. Rio de Janeiro: Tempo Brasileiro.

HOOKS, b. 2000. Feminism is for Everybody: Passionate Politics. London: Pluto Press.

JOHNSON, P. 2001. Distorted communications: feminism's dispute with Habermas. In: Philosophy and Criticism. vol 27 no $1 \cdot$ pp. 39-62.

MACKINNON, C. 1987. Feminism Unmodified: Discourses on Life and Law. Cambridge: Harvard University Press.

1991. Toward a Feminist Theory of the State. Cambridge: Harvard University Press.

MEEHAN, J. 1995. Feminists read Habermas: Gendering the Subject of Discourse. New York: Routledge. 